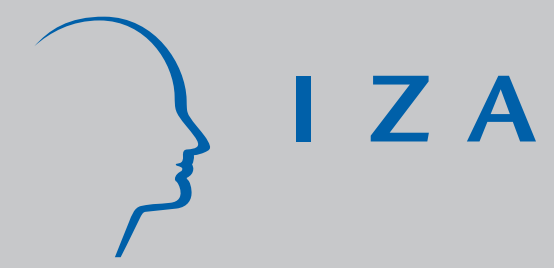

IZA DP No. 1075

Are J ob Search Programs a Promising Tool?

A Microeconometric Evaluation for Austria

Andrea Weber

Helmut Hofer

March 2004 


\title{
Are Job Search Programs a Promising Tool? A Microeconometric Evaluation for Austria
}

\author{
Andrea Weber \\ Institute for Advanced Studies, Vienna \\ and IZA Bonn \\ Helmut Hofer \\ Institute for Advanced Studies, Vienna
}

\author{
Discussion Paper No. 1075 \\ March 2004
}

\author{
IZA \\ P.O. Box 7240 \\ 53072 Bonn \\ Germany \\ Phone: +49-228-3894-0 \\ Fax: +49-228-3894-180 \\ Email: iza@iza.org
}

Any opinions expressed here are those of the author(s) and not those of the institute. Research disseminated by IZA may include views on policy, but the institute itself takes no institutional policy positions.

The Institute for the Study of Labor (IZA) in Bonn is a local and virtual international research center and a place of communication between science, politics and business. IZA is an independent nonprofit company supported by Deutsche Post World Net. The center is associated with the University of Bonn and offers a stimulating research environment through its research networks, research support, and visitors and doctoral programs. IZA engages in (i) original and internationally competitive research in all fields of labor economics, (ii) development of policy concepts, and (iii) dissemination of research results and concepts to the interested public.

IZA Discussion Papers often represent preliminary work and are circulated to encourage discussion. Citation of such a paper should account for its provisional character. A revised version may be available on the IZA website (www.iza.org) or directly from the author. 


\section{ABSTRACT}

\section{Are Job Search Programs a Promising Tool? A Microeconometric Evaluation for Austria*}

In Austria job search programs were introduced on a large scale in 1999. These programs aim at activating unemployed at an early stage and bringing them back to work by training job search related skills. We evaluate the impact of active labour market programs in Austria on individual unemployment durations, and allow program effects to vary between job search programs and formal training programs. We use the timing-of-events method which estimates the program effect as a shift in the transition rate from unemployment to jobs at the moment of program entry. We find that participation in job search programs significantly reduces unemployment durations, whereas formal training programs have a negative effect on unemployment durations.

JEL Classification: C14, C41, J64, J68

Keywords: active labour market policy, treatment effect, multivariate duration model

Corresponding author:

Andrea Weber

Department of Economics and Finance

Institute for Advanced Studies

Stumpergasse 56

1060 Vienna

Austria

Tel.: +43159991147

Fax: +43159991163

Email: andrea.weber@ihs.ac.at

\footnotetext{
* The authors thank Rudolf Winter-Ebmer and seminar participants in Innsbruck and Linz for comments. Marius Wilk and his colleagues from the AMS generously helped with data collection and insider information. Tsvetan Bikov is thanked for help with data processing. Financial support for this research was granted from the Jubiläumsfonds of the Austrian National Bank grant No. 9242.
} 


\section{Introduction}

A growing evaluation literature on active labour market programs (ALMP) comes to rather sobering conclusions concerning their overall effectiveness (Calmfors et al., 2001; Heckman et al., 1999; Kluve and Schmidt, 2002). These results cause problems for the justification of public expenditures for ALMP, which are especially high in Europe. In detailed investigations it can be found, however, that not all measures are equally unsuccessful. Consequently, the strategy is to compare different concepts and designs and their impacts on several target groups to single out the most promising measures. In an overview Martin and Grubb (2001) assess principles in order to maximise the effectiveness of ALMP in the OECD countries (see also Martin and Grubb, 2000). According to them, a high priority should be given to in-depth counselling, job-finding incentives, and job search assistance programs. Public training programs should be kept on small scale and be well targeted to the specific needs of both job seekers and employers.

In Austria active labour market policy is traditionally focused on training programs. Their aim is to improve individual skills and chances in the labour market with a long term perspective. ${ }^{1}$ In 1999 and 2000, following the recommendations towards job search assistance programs, a new type of programs were introduced on a large scale. The main goal of the job search programs is to activate and encourage unemployed individuals to move quickly out of unemployment by increasing the effectiveness of job search. Due to the low cost, in comparison to training programs, job search programs can be made available to a much wider target group. It was planned to send every new entrant into unemployment to a course before the fourth month of the spell had elapsed. During our investigation period (1999-2001) the training and job search programs were run almost independently of each other. Training plans involving an alternating series of job search and training programs were only introduced in later years. Hence the Austrian system provides an interesting setup for a direct comparison of two quite contrasting program concepts in a single labour market.

In the literature formal training programs are widely discussed (Calmfors et al., 2001; Heckman et al., 1999). It is regarded as one of their major drawbacks that training participants are locked in the program situation. While attending courses they lose labour force attachment and reduce their search effort. In the

\footnotetext{
${ }^{1}$ Zweimüller and Winter-Ebmer (1996) evaluated public training programs in the 1980's and found positive treatment effects on employment stability.
} 
end a costly reintegration is necessary which lowers the overall skill enhancement effect of the program. Job search programs are a relatively new concept and less researched. Recently they received considerable interest in the reforms of the US welfare system (Bloom and Michalopoulos, 2001; Hotz et al., 2002). The motivation for the "work first" approach is to move recipients out of passive benefit claimant status and to shift the training component back to the employers. European studies on job search programs include Blundell et al. (2003); Winter-Ebmer (2000).

In this paper we use a model for individual program participation which allows for a direct comparison of the effects of training and job search programs. We focus on the evaluation of immediate employment effects in terms of transitions from unemployment to regular jobs as the reduction of unemployment is the stated goal of ALMP in Austria. By investigating the dynamics of the program effects we can gain important information on how the different programs work. We allow the program effect to vary over time and check whether there is a lock-in effect for training programs and if the effects of job search deteriorate over time. In order to see which target groups benefit most from the different programs we investigate how the program effects vary by individual characteristics.

The question how participation in ALMP affects labour market outcomes of participants has been subject to substantial debate in the econometric literature (Heckman et al., 1999). The main problem can be regarded as one of missing data: at any point in time an individual is either a participant of the program or not, but not both. Labour market outcomes for participants may be systematically different from non-participants for reasons that are unobservable to the researcher, this is called the selection problem. The ideal setup for evaluation would be a social experiment, where individuals are randomly assigned to participate in a program. Social experiments are a standard tool in the US. However, they are expensive and difficult to implement and therefore relatively uncommon in Europe (for examples see Rosholm and Skipper, 2003; van den Berg and van der Klaauw, 2001).

Several econometric methods have been developed to deal with the evaluation problem in non-experimental data (for reviews see among others Blundell and Costa-Dias, 2000; Heckman et al., 1999). Abbring and van den Berg (2003) introduce a method based on the exact timing of the program during an unemployment spell and show that the program effect is identified by the variation in the time of program entry. This method does not rely on assumptions on the observable variables, like the more standard method of matching, but the 
selection into the program is allowed to depend on unobservable individual characteristics as well. The timing-of-events method models transitions from unemployment to employment and transitions into programs in a multivariate hazard model. ${ }^{2}$ The model can be easily extended to differentiate the effects by program types. Hence it provides a consistent framework for a comparison of training and job search programs in the Austrian system. The method also allows inference on the time dynamics of the program effects. Further arguments for our choice of the evaluation method are the following: We use data from administrative sources, which contain precise information on the timing of unemployment and program participation, along with the individual's labour market history. The programs we consider are designed for all groups of unemployed, hence no natural comparison groups arise. In the Austrian system decisions on program participation are subject to discretionary power of the advisors in the employment office to a large extent. As we do not have all the information underlying their decisions, the assumption that selection into programs is completely explained by observable variables might be hard to justify.

\section{Labour market policy in Austria}

The Austrian labour market policy has two components: a benefit system that supports individuals while unemployed (see Appendix) and various active labour market programs offered in order to facilitate the re-employment of unemployed job-seekers. Austrian expenditures on active and passive labour market policies amounted to $1.57 \%$ of GDP in 2000 . The amount allocated to active labour market policies was $0.51 \%$ of GDP. These figures are small in international comparison; spending on active labour market policy in the OECD average was $0.76 \%$ of GDP (OECD, 2002).

Active labour market policy includes counselling, placement and a broad range of active labour market programs. The main strategy of ALMP in Austria aims at improving individual skills. Of all persons treated by ALMP in 2000, $84 \%$ attended training programs (formal training or job search). Employment subsidies were granted to about $8 \%$ of treated persons. ${ }^{3}$ Finally a share of $8 \%$ received other kinds of treatment in the form of child care assistance, support for unemployed to start an enterprise or special counselling (Arbeitsmarktservice

\footnotetext{
${ }^{2}$ The timing-of-events method has been recently applied in a number of evaluation studies, including Abbring et al. (1997); Bolvig et al. (2003); Lalive et al. (2002); Lubova and van Ours (1999); Richardson and van den Berg (2001).

${ }^{3}$ Expenditures for ALMP were distributed by $59 \%$ for training programs, $32 \%$ for employment subsidies, and 9 for the other measures
} 
Österreich, 2001)

Training programs focus on education and on qualification enhancement of participants. Courses offered are either vocational training courses which result in a certified education equivalent to an apprenticeship degree. Other courses train specific skills like languages or computer abilities. Course durations vary from 4 weeks to one year according to the course type. Training courses are rather expensive per trainee. Therefore they can only be provided for a small fraction of the unemployed and the targeting of participants is complicated. For the participants training courses are time intensive and participation may reduce their search effort and attachment to the labour market.

Following the guidelines of the European Employment Strategy a second group of programs has been implemented (European Commission, 1998). These are so-called job search programs aiming at the activation of unemployed individuals at an early stage. These programs are not focused on specific target groups but should be available for the majority of the unemployed. Job search programs are designed to increase search effort and search efficiency by motivating and encouraging participants. The programs should lead to immediate transitions into employment either during the course or shortly afterwards. During the course job application practices (writing application letters, behaviour in job talks) are trained. Course durations are 6 weeks ( 7 weeks in 2000), but not full time: three course days during the first week and one day during each of the following weeks. In contrast to training programs participation in job search courses is mandatory and noncompliance is subject to benefit sanctions. Job search programs were first introduced on a large scale in 1999 and 2000 under the project name "job-coaching" (Schernhammer and Adam, 2002). The ambitious aim was that every new entrant into unemployment should be enrolled into a course before completing the first four months of unemployment. The short time between installment and begin of this large scale program led, however, to a number of administrative difficulties. In some locations also unemployed with longer spell durations had to be admitted to fill up existing courses, in others slots for short-time unemployed were missing.

To be eligible for ALMP participation in Austria a person must be unemployed, or face the risk of becoming unemployed. Since the Austrian Ministry of Social Affairs does not specify the eligibility criteria more narrowly, this leaves a great deal of discretion to the program administrators. The guidelines instruct the employment office advisors actively to offer training to the unemployed who lack specific skills, and in particular to individuals with placement disadvantages (school dropouts, long-term unemployed, disabled, women with long work 
interruptions). During training participation, individuals receive compensation which amounts to the level of unemployment benefits.

\section{Model and estimation method}

The timing-of-events method uses a multivariate duration specification, modelling simultaneously two processes both starting with the beginning of the unemployment spell. They are the process measuring the time until a transition from unemployment to employment occurs and the process measuring the time until program participation. If an individual finds a job before entering into a program, the time until participation is treated as right censored. In this way selection into the program is explicitly modelled. When the person enters the program, she is still unemployed but the hazard rate out of unemployment is allowed to change. This change defines the program effect we want to measure. The method also takes into account that program participation and the decision to take a job are affected by unobserved factors, which may be correlated. The identification problem is then to distinguish between selection effects and the causal program effect. ${ }^{4}$

\subsection{Timing-of-events method}

To formalise the model, let the random variable $T_{u}$ denote the duration of unemployment, and $T_{p}$ the duration from the start of unemployment until participation in an ALMP. We focus on the hazard rates of $T_{u}$ and $T_{p}$ of that individual. The hazard rate of a duration variable is the rate at which the spell is completed at time $t$ given that it has not been completed before, as a function of $t$. It provides a full characterisation of the duration distribution (Lancaster, 1990; van den Berg, 2001).

We assume that the individual distribution of $T_{u}$ can vary with observed and unobserved explanatory variables $x$ and $v_{u}$, respectively. Let $t_{p}$ denote the realisation of $T_{p}$, the time until program entry. For an unemployed individual the transition rate from unemployment to employment at $t$ conditional on $x, v_{u}$ and $t_{p}$ is denoted by $\theta_{u}\left(t \mid x, t_{p}, v_{u}\right)$ and is assumed to have a Mixed Proportional

\footnotetext{
${ }^{4}$ In this approach we assume that an individual can be in two states, unemployment and employment. In the literature several approaches have been used. Bonnal et al. (1997) model employment, unemployment, participation in different programs each as a separate state and compare transitions between the states.
} 
Hazard (MPH) specification,

$$
\theta_{u}\left(t \mid x, t_{p}, v_{u}\right)=\lambda_{u}(t) \exp \left(x^{\prime} \beta_{u}+\delta I\left(t>t_{p}\right)+v_{u}\right)
$$

in which $\lambda_{u}(t)$ represents the individual duration dependence of the hazard. Program entry at $t_{p}$ is expressed by the indicator $I\left(t>t_{p}\right)$ which takes the value one for program participants; $\delta$ measures the program effect. The effect of the explanatory variables is given by $\beta$. We assume that $x$ is not time-varying. The specification summarises some important assumptions on the program effect. First, we assume that program participation does not affect the transition rate from unemployment to employment before the moment of the program start. Second, we do expect that the program, once it has started has a constant and permanent effect on the hazard rate out of unemployment. Third, we assume that the multiplicative effect of program participation is the same for every type of individual. In the final specification we will take into account that different types of programs as defined by the Austrian ALMP system may have different effects (see below Section 3.3). We will also check the sensitivity of the specification by estimating alternative models to test whether the program effects vary over time and for different population groups.

Let $t_{u}$ denote the realised unemployment duration. The conditional unemployment duration density function $f_{u}\left(t_{u} \mid x, t_{p}, v_{u}\right)$ can be written as

$$
f_{u}\left(t_{u} \mid x, t_{p}, v_{u}\right)=\theta_{u}\left(t_{u} \mid x, t_{p}, v_{u}\right) \exp \left(-\int_{0}^{t_{u}} \theta_{u}\left(s \mid x, t_{p}, v_{u}\right) d s\right)
$$

Next, we incorporate the duration until the start of an ALMP into the model. Consider the rate at which the individual enters the first program, from the moment she enters the current spell of unemployment. We assume the hazard into the program varies with observed and unobserved characteristics $x$ and $v_{p}$. The rate is denoted by $\theta_{p}\left(t \mid x, v_{p}\right)$ and it is also assumed to have a MPH specification

$$
\theta_{p}\left(t \mid x, v_{p}\right)=\lambda_{p}(t) \exp \left(x^{\prime} \beta_{p}+v_{p}\right)
$$

in which $\lambda_{p}(t)$ represents the individual duration dependence of the hazard. The density of $T_{p} \mid x, v_{p}$ associated with the distribution defined by (3) can be 
expressed analogously to equation (2)

$$
f_{p}\left(t_{p} \mid x, v_{p}\right)=\theta_{p}\left(t_{p} \mid x, v_{p}\right) \exp \left(-\int_{0}^{t_{p}} \theta_{p}\left(s \mid x, v_{p}\right) d s\right)
$$

The joint distribution of $T_{u}, T_{p} \mid x, v_{u}, v_{p}$ is fully determined by (2) and (4). Conditional on $x, v_{u}, v_{p}$ the only possible relation between the variables $T_{u}$ and $T_{p}$ is by way of the direct program effect on the transition rate from unemployment to employment. This means that if $\delta=0$ then, conditional on $x$, the variables $t_{u}$ and $t_{p}$ are only dependent if $v_{u}$ and $v_{p}$ are dependent.

In order to complete the model specification we need to make assumptions on the distribution of the unobservable variables $v_{u}$ and $v_{p}$. Especially the correlation between them is important for the model interpretation. In the case of independence of $v_{u}$ and $v_{p}$ we have a duration model for $t_{u}$ with a time-varying regressor $I\left(t>t_{p}\right)$ which is orthogonal to $v_{u}$. In this case no selection into the program occurs. In another case let us assume that $v_{u}$ is positively related to $v_{p}$. This means that individuals who get into a program early have on average a larger $v_{u}$ than individuals who get into a program later during their unemployment spell. So the correlation implies that they also have on average a larger transition rate to employment. Or in other words, individuals with favourable employment prospects are selected into the program. Disregarding the correlation in unobservables in a model assuming that getting into a program is independent from $x$ and $v_{u}$, the estimate of $\delta$ will be affected. Specifically, $\delta$ will be overestimated. For the case of negative correlation, or negative selection into programs, the reverse is possible.

Let $G$ denote the joint distribution of $v_{u}, v_{p}$, in the inflow into unemployment. A specification of $G$ together with the specification of the distribution of $T_{u}, T_{p} \mid x, v_{u}, v_{p}$ fully determines the distribution of $T_{u}, T_{p} \mid x$. Abbring and van den Berg (2003) show that the model in (2) and (4) is non-parametrically identified. They also show that we can identify models in which $\delta$ is allowed to vary with $x$ or with elapsed duration after program entry. Thus, the restriction of a constant and permanent effect of program participation is indeed testable. The intuition of the identification is that the unobserved individual characteristics are constant throughout the unemployment spell whereas the program effect only sets in at program entry. By the variation in program entry times and unemployment durations it is hence possible to disentangle the two effects. 


\subsection{Compatibility between the Austrian ALMP system and model assumptions}

The crucial assumptions for the Abbring and van den Berg (2003) identification result are, apart from the functional form assumption underlying the MPH specification of the hazard rates, that variation in the entry times into the program occurs, and that there is no advance notice of the program. We try to find justifications for these assumptions in the Austrian system.

The variation in entry dates into programs is given in our data. Although several programs are targeted at unemployed of specific elapsed durations, it proves difficult to generate homogeneous groups of participants in practice. For example, job search programs aimed at short term unemployed between the third and fourth months of their spell. In practice unemployed with spell durations from 1 to 12 months were admitted to those programs.

In order to guarantee that the job hazard rate is shifted only at the entry date into the program, it is necessary to assume that the unemployed have no advance notice of program participation. They may well be aware of the probability that they will be enrolled into a program, but they may not be informed about the exact date. This information would influence their strategy, either not to search for jobs and wait for the program start or to increase search effort in order to avoid program participation. In the Austrian system enrolment into training programs is based on discussions between the unemployed and the employment office advisor. In many cases a formal application or even an entrance exam are required. This means that notification of program participation can only be given a short time before the program start. At least this time span should be short compared to the unemployment duration. For job search programs the plan was to notify participants within one months before program start. In practice this was not a ways possible. Many participants were notified by mail a very short time before the program started in order to fill up courses. In other cases unemployed were assigned to the courses a long time in advance (Schernhammer and Adam, 2002). In these cases the assumption of no anticipation might be violated, but unfortunately data on the dates of notification are not available. ${ }^{5}$ In order to eliminate any effects of advance notice of employment transitions which is the case for temporary layoffs we removed all individuals who returned to their previous employer after unemployment from the sample.

\footnotetext{
${ }^{5}$ If these had been available we could have investigated the effects of a threat of a program like Black et al. (2003)
} 


\subsection{Implementation}

As indicated above we want to allow different program types to have different effects on the unemployment duration. In order to avoid substitution effects between different programs, we specify a model that incorporates all program types. Specifically, our data allow us to distinguish between three program types: training programs, job search programs, and a residual group of other programs (see Section 4). The model introduced above (equations (1)-(4)) is extended by replacing the single process measuring time until program entry $T_{p}$ by three different processes measuring the time until entry into each program type separately. They are denoted by $T_{p 1}, T_{p 2}, T_{p 3}$. Upon entry into one type of program the other two processes are treats as right censored. The index $p 1$ stands for training program, $p 2$ stands for job search program, and $p 3$ for other program. We model the hazards into each type of program $\theta_{p 1}, \theta_{p 2}, \theta_{p 3}$ analogous to (3); they are affected by different unobservable variables $v_{p 1}, v_{p 2}, v_{p 3}$ but the same observable characteristics $x$. The program effect is defined by the type of the first program the individual enters during her unemployment spell. In the hazard rate out of unemployment, equation (1), it is measured via three different parameters by transforming

$$
\begin{aligned}
\delta I\left(t_{u}>t_{p}\right)= & \delta_{1} I\left(t_{u}>t_{p 1}, t_{p 2}>t_{p 1}, t_{p 3}>t_{p 1}\right)+ \\
& \delta_{2} I\left(t_{u}>t_{p 2}, t_{p 1}>t_{p 2}, t_{p 3}>t_{p 2}\right)+ \\
& \delta_{3} I\left(t_{u}>t_{p 3}, t_{p 1}>t_{p 3}, t_{p 2}>t_{p 3}\right) .
\end{aligned}
$$

We specify piecewise constant baseline hazards as

$$
\lambda_{k}(t)=\exp \left(\sum_{i=1}^{m} \lambda_{k i} I_{i}(t)\right) \quad k=u, p 1, p 2, p 3
$$

where $i=1, \ldots, m$ are subscripts for time intervals and $I_{i}(t)$ are time-varying dummy variables, for the intervals: 0-1 months, 1-2 months, 2-5 months, 512 months, over 12 months. Because we also estimate a constant term, we normalise $\lambda_{k 1}=1$.

The joint distribution of unobserved characteristics $G\left(v_{u}, v_{p 1}, v_{p 2}, v_{p 3}\right)$ is assumed to take on a multivariate discrete distribution. We assume that each transition rate has two points of support $\left(v_{u a}, v_{u b}\right)$ for the transitions from unemployment into employment, $\left(v_{p i a}, v_{p i b}\right)$ for the transitions into the programs $i=1,2,3$. This implies that the joint distribution has 16 mass points. The 
associated probabilities are denoted as

$$
\begin{array}{rc}
P\left(v_{u}=v_{u a}, v_{p 1}=v_{p 1 a}, v_{p 2}=v_{p 2 a}, v_{p 3}=v_{p 3 a}\right) & =p_{a a a a} \\
P\left(v_{u}=v_{u a}, v_{p 1}=v_{p 1 a}, v_{p 2}=v_{p 2 a}, v_{p 3}=v_{p 3 b}\right) & =p_{a a a b} \\
\vdots & \\
P\left(v_{u}=v_{u b}, v_{p 1}=v_{p 1 b}, v_{p 2}=v_{p 2 b}, v_{p 3}=v_{p 3 b}\right) & =p_{b b b b}
\end{array}
$$

In the estimation procedure we actually estimate the transformed probabilities $q_{j}, j=a a a a, a b a a, \ldots, b b b b$ which are implicitly defined by

$$
p_{j}=\frac{\exp \left(q_{j}\right)}{\sum_{i=a a a a}^{b b b b} q_{i}}
$$

Because the $p_{j}$ sum to one, we normalise by taking $q_{b b b b}=0$. Estimating $q_{j}$ instead of $p_{j}$ has the advantage that no boundary restrictions have to be imposed on the parameter space.

When estimating the full model we have problems with estimating all the unobserved heterogeneity terms. We thus impose the restriction that the unobserved heterogeneity terms of the different programs are perfectly related. ${ }^{6}$ Hence only $p_{a a a a}, p_{a b b b}, p_{b a a a}$ and $p_{b b b b}$ are different from 0 .

\section{Data}

We use data on individual labour market careers which combine information from the social security records and from registers of the Austrian public employment office (AMS). The set under consideration includes the total inflow into unemployment from March to August 1999. A special feature of the Austrian labour market are high seasonal fluctuations in employment owing to the importance of tourism and construction sectors in the economy. Therefore the spring/summer inflow period was selected to minimise conflicts with seasonal unemployment. During the inflow period we observe 245,234 individuals. From the AMS registers we use information on personal characteristics of the individuals. In addition all ALMP spells for these persons during the years 1997 to 2001 are collected. From the social security records we match employment and

\footnotetext{
${ }^{6}$ Under this restriction a test for correlation of the unobserved heterogeneity terms for unemployment duration and program entry is given by the hypothesis $q_{a a a a}=q_{a b b b}+q_{b a a a}$.
} 
wage histories for the period 1988 to 2001 , which are given on a daily basis.

For the empirical analysis we select the first unemployment spell during the inflow period (March to August 1999) for each individual. From the ALMP spells we select the first program spell during the unemployment spell and mark these individuals as program participants. Closely connected with seasonal employment is the phenomenon of temporary layoffs, i.e. unemployment spells terminated by reemployment with the former employer. Hence we exclude from the analysis all workers who returned to their previous employer after unemployment (19\% excluded). ${ }^{7}$ Further we only consider individuals between 20 and 50 years of age ( $16 \%$ excluded). Younger individuals may not have finished their education. For individuals over 50 years special rules for unemployment benefits and early retirement apply. The reduced set includes 164,901 individuals. The empirical estimations are based on an $8 \%$ subsample of this set which includes 13,283 individuals. ${ }^{8}$ Descriptive statistics of all variables are given in Table 1.

In the sample a share of $19 \%$ of the unemployed are observed to participate in an ALMP during the unemployment spell. Program participants differ from the average unemployed with respect to their mean unemployment durations which are more than twice as long. Among program participants we find more women and individuals with Austrian nationality than in the complete sample. We also find evidence for recurrent program participation as the average number of ALMP spells before the selected unemployment spell is much higher for program participants. Labour market histories in the 2 years before the unemployment spell were less fortunate for program participants. This can be seen from the number of employment spells or the share of time unemployed during this period.

If the unemployment spell ended in a transition to a job the spell is considered to be completed. If the unemployment spell ended in the transition to another state (e.g. maternity leave, out of labour force, mothers with young children) it is considered to be censored. In our sample we observe a share of $33 \%$ censored unemployment spells. Empirical hazard rates for the transitions to jobs are shown in Figure 1. The job hazard rate for non-program participants reaches a peak of $11 \%$ between 30 and 60 days of unemployment and drops sharply afterwards. The decrease in the job hazard rate slows down after about 100 days when the hazard rate has fallen to half of the maximum value. ALMP

\footnotetext{
${ }^{7}$ These individuals fully anticipate their unemployment duration, which contradicts with the model assumptions.

${ }^{8}$ The estimation results were confirmed by comparing different subsamples.
} 
participants experience increasing job hazard rates during the first half year of unemployment. Afterwards their rate flattens and decreases slowly. In Figure 2 the hazard rate of entry into a ALMP has 2 peaks. One after a duration of about 4 months and a second after one year.

Information on ALMP participants in our sample is given in Table 2. We distinguish between training and job search assistance programs. Due to a problem with the classification of ALMP in the records of the Austrian public employment service not all program spells could be classified and we have a residual group of unclassified programs. This group of programs is supposed to include a very heterogeneous set of measures, either programs targeted at special groups of unemployed (disabled, long-term unemployed) or unclassified training or job search programs. Hence in the sample a share of $24 \%$ of program participants is observed to attend a training program, $31 \%$ can be classified into job search programs and the residual group attends an unclassified program.Mean unemployment durations for all program participants are about 10 months. Training programs have an average duration of 2 months, but with a high variation. Job search programs have shorter durations of about one month on average. Entry into a training program occurs on average after 3-4 months of unemployment. Entry into job search programs is on average after 4-5 months. Note that there is a high variation in the timing of program entry as can be seen from the standard deviations.

\section{Results}

We start the discussion of estimation results with a basic model. This model differentiates between the effects of all three program types (training programs, job search programs and other programs). Unobserved heterogeneity is allowed to play a role in determining the hazards. The program effects are measured at program entry and we assume that the effects are constant for the remaining unemployment spell and homogeneous for all individuals. We then contrast the results of the basic model to a model where no selection is allowed, the correlation of unobserved heterogeneity terms for unemployment exit and program entry is set to zero. We compare some alternative specifications to analyse the sensitivity of the results with respect to the assumptions. One model alternative allows for heterogeneous program effects by population groups. The other alternative deals with the variation of program effects over time. 


\subsection{Basic model}

Column A in Table 3 gives the main results for the basic model. The parameters of primary interest are $\delta_{p i}$ the program effects. A positive value of $\delta_{p i}$ increases the hazard rate out of unemployment and therefore corresponds to a shorter unemployment duration. Hence a positive value can be interpreted as a positive program effect. For training programs $\delta_{p 1}=-0.126$. This means that training programs reduce the transition rate from unemployment to employment by $12 \%$ $\left(\exp \left(\delta_{p 1}\right)-1\right)$. For job search programs the effect is positive. We find that entry into a job search program increases the job hazard by $67 \%$. For other programs being an indistinguishable mix of the two former we do not find any significant effect.

The program effect on mean unemployment duration depends on the moment at which the program occurs. For example consider an individual who has an expected unemployment duration of 130 days (equal to the sample mean) without entering a program. If job search is given to her within the first month the total mean unemployment duration is reduced by approximately one third. If the same program is given before the fourth month of unemployment, mean duration is reduced by $20 \%$.

To be able to compare the program effect of job search to the existing literature we calculate a "treatment effect on the treated". We consider all individuals who were admitted to a program and their estimated probabilities of finding a job within four months of program start. The treatment effect is defined by the increase in the probability of leaving unemployment relative to the counterfactual of no program participation. According to our results the probability of finding a job within four months net of the program effect is 0.65 for job search participants. The probability is increased by $15 \%$ through program participation. For British unemployed youths Blundell et al. (2003) report a treatment effect of $20 \%$ for a job search program. Bloom and Michalopoulos (2001) survey 29 different initiatives associated to the welfare to work reform. They report that treatment effects of job search related programs vary between $10 \%$ and $50 \%$. The British and US programs have target groups which are more disadvantaged and differ from the average Austrian unemployed admitted to job search, however. But still the size of our program effect seems to be in line with international results.

From the estimated parameters of the unobserved heterogeneity distribution we learn that after controlling for all observable characteristics we can still distinguish two different groups of unemployed. Concerning transitions from unem- 
ployment to jobs, there is a group of about $15 \%$ of all unemployed, who have hazard rates into a job which are five times lower than the others'. Similarly we can distinguish groups for the hazards into each of the program. The correlation between the unobserved heterogeneity terms in the hazard rate from unemployment to jobs and the hazard into training programs is 0.162 . This means that positive selection into training programs occurs. In the case of job search programs the correlation between unobserved heterogeneity terms is negative. This can be interpreted in a way that unemployed with, ceteris paribus, longer expected unemployment durations were selected into these programs.

We contrast the results from the basic model to the incorrect specification where selection based on unobserved heterogeneity is omitted. The estimation results are given in column $\mathrm{B}$ of Table 3 . The changes in parameter estimates of the program effects reflect the correlations in the unobserved heterogeneity terms we discussed before. The positive selection into training programs results in an overestimation of the program effect in the incorrectly specified model. In the same way the program effect of job search programs is underestimated.

Let us turn to selected covariate effects on the hazard rates which are given in Table 4. From the results for the hazard rate into jobs, in the first column, we find that: Unemployment durations are longer for women and Austrian citizens. They shrink with the level of education, but rise with age. Recipients of both, unemployment benefits and unemployment assistance have longer unemployment durations. Interestingly, also the number of past ALMP spells (form 1997 until the current spell of unemployment) increases unemployment durations. We find an influence of the labour market career in the recent past (1997-1999) on the length of the current unemployment spell, but none form more distant events.

The composition of participants in training programs is determined by their hazard into the program. We find that women and Austrians are admitted to training programs at a higher rate. Education above the primary level helps in getting admitted, as well as age above 30 years. Non-benefit recipients have higher hazard rates into training-programs. The number of past program spells has a huge positive impact on the entry rate. We seem to be confronted with a phenomenon of program careers, where the same individuals are repeatedly admitted to programs. Both the recent and distant labour market histories of the individual have an impact on the hazard into training programs, especially the number of past unemployment spells.

Participants of job search programs seem to be selected by different criteria. 
Again Austrian citizens face high entry rates. But here benefit recipients, lowly educated unemployed and young people are preferred. The number of past program spells again plays a role, but the impact is not as high as for the entry rate into training programs. Past labour market outcomes, either in the recent or in the distant past, do not play a role in the selection of job search program participants. The complete estimation results for the basic model can be found in Table 7.

\subsection{Heterogeneous program effects}

So far we have assumed homogeneity of the treatment effects $\delta=\left(\delta_{p 1}, \delta_{p 2}, \delta_{p 3}\right)$ on the exit rate to employment over individuals and over time. We now allow for heterogeneous treatment effects. First, we let $\delta$ be different for certain population groups. Specifically we investigate whether the treatment effect varies between men and women, Austrians and individuals with foreign nationality, or individuals with compulsory education as opposed to higher educated individuals. ${ }^{9}$ Table 5 gives the estimated program effects for this model. We find considerable variation in the program effects. First of all, women profit more than men from all types of programs. We even find a positive overall program effect for women in training programs. Training effects are higher for Austrian citizens in all programs, but the coefficient is only significant for other programs. We also find a higher program effects for low educated individuals in training programs. This is remarkable as we noticed before that they are admitted to training programs at a lower rate. A chi-square test for the hypothesis that there is no heterogeneity can be rejected.

\subsection{Time variation in program effects}

In the previous models we assume the training effect sets in at the moment of entry into the program, and then remains constant over time. Now suppose there was a lock-in effect during program attendance, as a result of reduced search effort or the individual just wanting to finish the course before taking up employment. In the basic model we measure a combination of this lock-in effect and a skill-enhancement effect. In the next model specification we allow the program effect to vary over time. The sample mean program durations for all programs are about 2 months. So we let the program effect vary between

\footnotetext{
${ }^{9}$ To investigate the importance of the targeting job search programs towards short term unemployed Weber and Hofer (2004) study the dependence of the program effect on varying entry times in a similar setup
} 
the first half of an average course (0-30 days), the second half (30-60 days) course and the time after the course (more than 60 days). The estimation results are given in Table 6 . It shows that the program effect is always lowest during the first 30 days after program entry. For training programs we find a significantly negative effects during the first 60 days. But after that time the program effect turns positive. This hints at a pronounced lock-in effect. For job search programs the effect is small but significantly positive at program start. But from the second month on the full effect is attained. Given that job search programs usually last 6-7 weeks we can conclude that the full effect is at work already during the program and the lock-in effect is small if existent. The chi-square test again rejects the hypothesis of no heterogeneity.

\section{Conclusion}

In this paper we examine the effects of different types ALMP in the Austrian system. We distinguish between job search programs and formal training programs. The further try to motivate individuals to move back into employment by training mainly job search related skills and the latter aim at increasing employment relevant skills with a long-term perspective. We employ the timingof-events method and model the program effect as a permanent shift in the individual hazard rate from unemployment to jobs which occurs at the moment of program entry. This method also takes possible selectivity in the inflow into programs into account.

We find that the immediate employment effects differ substantially by program type. Job search programs increase the transition rate into jobs considerably. The probability of finding a job within four months is increased by $15 \%$ for job search participants. Training programs, on the other hand, have a small but negative effect on transitions into employment. Investigating the dynamics of the treatment effect we find that the negative effect from training programs is due to a lock in period of 60 days. After that training programs have a positive effect on the employment probability. Program effects differ for women and men. We find that women benefit from participation in all types of programs. There is even a positive overall program effect for women from training programs. Our results indicate that after controlling for all observable information, selection into programs by unobservable characteristics still occurs.

Overall we find strong and rather positive effects of ALMP in Austria, especially for job search programs. US evidence has been more optimistic for job 
search oriented programs especially if they are combined with training plans. In the period analysed in this paper training and job search programs were operated independently from each other. Even higher gains might be obtained if the program design would coordinate training and job search assistance activities. ${ }^{10}$ The mandatory nature of job search may also play a role in the positive outcome as compulsory sanction enforced schemes have often been found to be more effective than voluntary schemes. A further argument comes through the favourable macroeconomic conditions. During the years 1998-2000 the Austrian economy faced a period of strong economic growth, with high increases in employment and also in vacancies. It is debatable whether in a loose labour market job search could have been so successful.

There are several areas for further research. First, we do not consider longerterm effects of ALMP. A full evaluation needs to consider the stability of the jobs taken up after unemployment (see for example van Ours, 2000). Program types might differ in this respect. The data is not yet available to perform such an analysis. In this paper we do not consider any general equilibrium and wage effects which might play a role if the programs are operated on a large scale. Further, we find that repeated program participations (program careers) have a strong impact on the unemployment duration as well as on entry into further programs. Sofar we only considered a one-time program effect and neglect any dynamic effects of past programs on the choice of the next program and the employment outcome.

\section{References}

Abbring, J. H., van den Berg, G. J., 2003. The non-parametric identification of treatment effects in duration analysis. Econometrica 71, 1491-1517.

Abbring, J. H., van den Berg, G. J., van Ours, J. C., 1997. The effect of unemployment insurance sanctions on the transition rate from unemployment to employment. Working Paper Tinbergen Institute Amsterdam.

Arbeitsmarktservice Österreich, 2001. Geschäftsbericht 2000 , Wien.

Black, D. A., Smith, J. A., Berger, M. C., Noel, B. J., 2003. Is the threat of reemployment services more effective than the services themselves? evidence

\footnotetext{
${ }^{10}$ In the case of a special redundancy-training project in Austria Winter-Ebmer (2000) points out that the combination of orientation, training and job search assistance contributed to the positive program effect.
} 
form random assignment in the UI System. American Economic Review 93, $1313-1327$.

Bloom, D., Michalopoulos, C., 2001. How welfare and work policies affect employment and income: a synthesis of research. MDRC May.

Blundell, R., Costa-Dias, M., 2000. Evaluation methods for non-experimental data. Fiscal Studies 21, 427-468.

Blundell, R., Costa-Dias, M., Meghir, C., van Reenen, J., 2003. Evaluating the employment effects of a mandatory job search program. University College London Discussion Papers in Economics (03-05).

Bolvig, I., Jensen, P., Rosholm, M., 2003. The employment effects of active social policy in Denmark. IZA Discussion Paper Series (736).

Bonnal, L., Fougère, D., Sèrandon, A., 1997. Evaluating the impact of French employment policies on individual labour market histories. Review of Economic Studies 64, 683-713.

Calmfors, L., Forslund, A., Hemström, M., 2001. Does active labour market policy work? lessons from the Swedish experiences. Swedish Economic Policy Review 8, 61-124.

European Commission, 1998. Employment policies in the EU and in the Member States. Joint Report 1998 .

Heckman, J., Lalonde, R., Smith, J., 1999. The economics and econometrics of active labor market programs. In: Ashenfelter, O., Card, D. (Eds.), Handbook of Labor Economics. Vol. 3a. North Holland, Amsterdam.

Hotz, V. J., Imbens, G. W., Klerman, J. A., 2002. The long-term gains form GAIN: a re-analysis of the impacts of the Californian GAIN program Paper presented at the 10th international conference on Panel Data, Berlin.

Kluve, J., Schmidt, C. M., 2002. Can training and unemployment subsidies combat European unemployment. Economic Policy (35), 409-448.

Lalive, R., van Ours, J. C., Zweimüller, J., 2002. The impact of active labor market programs on the duration of unemployment. Working Paper (41), institute for Empirical Research in Economics University of Zurich.

Lancaster, T., 1990. The econometric analysis of transition data. Cambridge University Press, Cambridge, UK. 
Lubova, M., van Ours, J. C., 1999. Effects of active labor market programs on the transition rate from unemployment into regular jobs in the Slovak Republic. Journal of Comparative Economics 27, 90-112.

Martin, J. P., Grubb, D., 2000. What works among active labour market policies: evidence from OECD countries' experience. OECD Economic Studies $30,70-114$.

Martin, J. P., Grubb, D., 2001. What works and for whom: a review of OECD countries' experiences with active labour market policies. Swedish Economic Policy Review 8, 9-56.

OECD, 2002. Employment Outlook 2002 , Paris.

Richardson, K., van den Berg, G., 2001. The effect of vocational employment training on the individual transition rate from unemployment to work. Swedish Economic Policy Review 8, 175-213.

Rosholm, M., Skipper, L., 2003. Is labour market training a curse for the unemployed? Evidence from a social experiment. IZA Discussion Paper (716).

Schernhammer, B., Adam, U., 2002. Evaluierung von Jobcoaching 2000. AMS Report (31).

van den Berg, G., 2001. Duration models: specification, identification, and multiple durations. In: Heckman, J., Leamer, E. (Eds.), Handbook of Econometrics. Vol. 5. North Holland, Amsterdam.

van den Berg, G. J., van der Klaauw, B., 2001. Counselling and monitoring of unemployed workers: theory and evidence from a controlled social experiment. IZA Discussion Paper (374).

van Ours, J. C., 2000. Do active labor market policies help unemployed workers to find and keep regular jobs? In: Lechner, M., Pfeiffer, F. (Eds.), Econometric Evaluation of Labor Market Policies. Physica, Heidelberg.

Weber, A., Hofer, H., 2004. Employment effects of early interventions on job search programs. mimeo (IHS).

Winter-Ebmer, R., 2000. Long-term consequences of an innovative redundancyretraining project: The Austrian Steel Foundation. Universtity of Linz Working Paper (29).

Zweimüller, J., Winter-Ebmer, R., 1996. Manpower training programmes and employment stability. Economica 63, 113-130. 


\section{Appendix: The Austrian system of unemployment in- surance}

Unemployment insurance is provided in the form of unemployment benefits (Arbeitslosengeld, UB) and unemployment assistance (Notstandshilfe, UA). Eligibility for UB depends on work experience and age. The minimum duration of benefits is 12 weeks, but if the unemployed person has worked at least 486 weeks in the last 15 years and is above the age of 50 , the period of benefits can be as long as 52 weeks. The monthly amount received is $55 \%$ of the net monthly earnings plus allowances for dependent children. There is an upper limit for the amount of UB, which flattens the replacement ratio considerably for high-income earners. Benefits are not taxed. Those who have exhausted unemployment benefits may be granted unemployment assistance. In principle, the amount of UA is about $92 \%$ of UB and it is means tested. The resulting amount is ultimately $78 \%$ of the UB amount on average. The duration of UA is six months, but can be extended after further examination. Voluntary quitters and workers discharged for misconduct are subject to a waiting period of 4 weeks before they can claim any benefits. 
Table 1: Descriptive Statistics, $8 \%$ subsample of total inflow into unemployment March-August 1999.

\begin{tabular}{|c|c|c|c|c|}
\hline & \multicolumn{2}{|c|}{ All unemployed } & \multicolumn{2}{|c|}{ ALMP participants } \\
\hline & Mean & Std.dev & Mean & Std.dev \\
\hline Unemployment duration & 127.19 & 173.60 & 294.16 & 238.02 \\
\hline Duration until program entry & & & 122.47 & 124.18 \\
\hline Program duration & & & 62.82 & 85.33 \\
\hline Censored unemployment spell & 0.33 & & 0.34 & \\
\hline Female & 0.48 & & 0.58 & \\
\hline Married & 0.44 & & 0.42 & \\
\hline Austrian & 0.85 & & 0.91 & \\
\hline \multicolumn{5}{|l|}{ Level of education } \\
\hline Compulsory school & 0.39 & & 0.39 & \\
\hline Vocational training & 0.48 & & 0.47 & \\
\hline High school and above & 0.09 & & 0.11 & \\
\hline Age (years) & 31.72 & 8.12 & 32.71 & 8.02 \\
\hline Unemployment benefit recipient & 0.60 & & 0.58 & \\
\hline Unemployment assistance recipient & 0.13 & & 0.22 & \\
\hline Number of past program spells & 0.06 & 0.35 & 0.31 & 0.76 \\
\hline \multicolumn{5}{|l|}{ Recent history 1997-1999 } \\
\hline Number of unemployment spells & 1.53 & 1.74 & 1.34 & 1.61 \\
\hline Percentage unemployed & 0.17 & 0.22 & 0.21 & 0.27 \\
\hline Number of employment spells & 2.23 & 1.85 & 1.79 & 1.61 \\
\hline Percentage employed & 0.57 & 0.36 & 0.54 & 0.38 \\
\hline Mean wage (Euro) & 1170.41 & 672.89 & 1117.71 & 712.87 \\
\hline St.dev wage & 191.43 & 172.52 & 73.77 & 135.36 \\
\hline \multicolumn{5}{|l|}{ Distant history $1988-1996$} \\
\hline Number of unemployment spells & 3.43 & 3.98 & 3.35 & 3.76 \\
\hline Percentage unemployed & 0.09 & 0.13 & 0.12 & 0.16 \\
\hline Number of employment spells & 5.05 & 4.18 & 4.52 & 3.69 \\
\hline Percentage employed & 0.47 & 0.31 & 0.48 & 0.32 \\
\hline Mean wage (Euro) & 1087.56 & 536.33 & 1110.64 & 546.08 \\
\hline St.dev wage & 191.44 & 172.52 & 186.7 & 173.45 \\
\hline Regional unemployment rate (NUTS 3) & 4.27 & 1.46 & 4.46 & 1.45 \\
\hline \multicolumn{5}{|l|}{ Region of residence } \\
\hline Wien & 0.24 & & 0.38 & \\
\hline Burgenland & 0.03 & & 0.03 & \\
\hline Kärnten & 0.08 & & 0.06 & \\
\hline Niederösterreich & 0.15 & & 0.13 & \\
\hline Oberösterreich & 0.16 & & 0.16 & \\
\hline Salzburg & 0.07 & & 0.03 & \\
\hline Steiermark & 0.13 & & 0.13 & \\
\hline Tirol & 0.09 & & 0.04 & \\
\hline Vorarlberg & 0.04 & & 0.03 & \\
\hline \multicolumn{5}{|l|}{ Occupation } \\
\hline Agriculture & 0.01 & & 0.01 & \\
\hline Manufacturing & 0.28 & & 0.28 & \\
\hline Construction & 0.07 & & 0.04 & \\
\hline Retail Sale & 0.15 & & 0.16 & \\
\hline Services & 0.07 & & 0.06 & \\
\hline Tourism & 0.16 & & 0.09 & \\
\hline Technical & 0.04 & & 0.05 & \\
\hline Office & 0.15 & & 0.24 & \\
\hline Health & 0.08 & & 0.08 & \\
\hline Number of observations & 13283 & & 2498 & \\
\hline
\end{tabular}

NOTE: Standard deviations are only given for non-dummy variables. 
Table 2: Descriptive Statistics of Active Labour Market Programs, program participants in $8 \%$ subsample of total inflow into unemployment 3-8/1999.

\begin{tabular}{lrrrrrrrr}
\hline & \multicolumn{2}{c}{ Training } & & & & \multicolumn{2}{c}{ Job search } & \multicolumn{2}{c}{ Other programs ** } \\
& Mean & Std.Dev & & Mean & Std.Dev & & Mean & Std.Dev \\
& & & & & & \\
& 283.33 & $(234.39)$ & 312.22 & $(251.19)$ & 287.62 & $(230.21)$ \\
Unemployment duration* & 105.55 & $(120.7)$ & 146.99 & $(133.41)$ & 114.74 & $(116.97)$ \\
Duration until program entry & 70.95 & $(94.56)$ & 41.64 & $(61.08)$ & 72.82 & $(91.55)$ \\
Program duration & & & & & & \\
& 589 & & 766 & & & 1143 & \\
Number of participants & 0.64 & & 0.65 & & 0.68 & \\
Transitions to employment (\%) & & & & & & & \\
& & & & & &
\end{tabular}

Note: ${ }^{*}$ Durations given in days.

${ }^{* *}$ Unclassified training and job search programs and other kinds of training and orientation. 
Table 3: Basic model: program effects and heterogeneity distribution

A

Parameter

Program Effects

Training

Job search

Other program

$-0.126$

0.515

$-0.032$
Heterogeneity distribution

Mass points

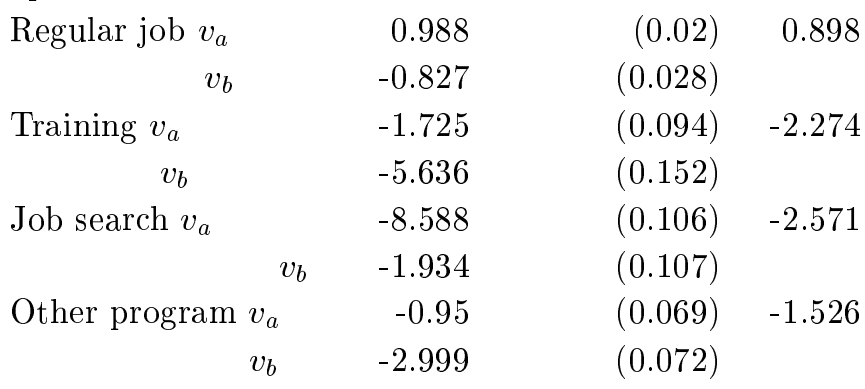

Probabilities

$\begin{array}{ll}p_{\text {aaaa }} & 0.276 \\ p_{\text {abbb }} & 0.572 \\ p_{\text {baaa }} & 0.056 \\ p_{\text {bbbb }} & 0.097\end{array}$

Correlations

job, training $\quad 0.162$

job, job search $\quad-0.162$

job, other program

Number of observations

13283

$-6032$

$\log$ Likelihood

0.162

$(0.011)$

$(0.011)$

$(0.011)$
B

Std.err $\underline{\text { Parameter Std.err }}$

$\begin{array}{ll}(0.049) & 0.011 \\ (0.041) & 0.344 \\ (0.037) & 0.126\end{array}$

(0.040)

NOTE: Column A: multivariate mixed proportional hazard model for unemployment duration and time until program entry; heterogeneous programs effects by program type; correlated unobserved heterogeneity in hazard rates; program effects are measured at program entry and constant for the remaining unemployment spell. Full estimation results given in table 7 .

Column B: like A but no correlation in unobserved heterogeneity in hazard rates. Standard errors in parentheses. 
Table 4: Basic model: effects of selected explanatory variables on the transition rates in regular jobs, training programs, job search programs, and other programs

\begin{tabular}{|c|c|c|c|c|}
\hline & Job & Training & Job search & Other \\
\hline Female & $-0.202^{*}$ & $0.286^{*}$ & 0.104 & $0.144^{*}$ \\
\hline Married & -0.010 & -0.033 & $-0.161^{*}$ & -0.084 \\
\hline Austrian & $-0.300^{*}$ & $0.659^{*}$ & $0.272^{*}$ & 0.129 \\
\hline \multicolumn{5}{|c|}{ Educational Level (High School and above) } \\
\hline Compulsory School & $-0.291 *$ & $-0.435^{*}$ & $0.277^{*}$ & 0.015 \\
\hline Apprenticeship & $-0.069^{*}$ & -0.010 & 0.167 & 0.005 \\
\hline UI benefit recipient & $-0.315^{*}$ & $-0.206^{*}$ & $0.299^{*}$ & -0.094 \\
\hline UA benefit & $-0.572^{*}$ & $-0.313^{*}$ & $0.555^{*}$ & 0.013 \\
\hline \multicolumn{5}{|l|}{ Age (40-50 years) } \\
\hline $20-30$ & $0.278^{*}$ & $-0.242^{*}$ & $0.207^{*}$ & -0.030 \\
\hline $30-40$ & $0.124^{*}$ & 0.123 & 0.165 & 0.189 \\
\hline Number of past program spells & $-3.192 *$ & $12.501^{*}$ & $3.778^{*}$ & $8.390^{*}$ \\
\hline \multicolumn{5}{|l|}{ Recent History 1997-1999 } \\
\hline Number of unemployment spells & $0.693^{*}$ & $1.216^{*}$ & -0.406 & $0.881^{*}$ \\
\hline Percentage unemployed & $-0.188^{*}$ & $-0.999^{*}$ & 0.181 & $-0.492^{*}$ \\
\hline Number of employment spells & $1.052^{*}$ & 0.628 & 0.359 & 0.063 \\
\hline Percentage employed & $0.509^{*}$ & 0.193 & 0.293 & $0.426^{*}$ \\
\hline Mean wage & $0.071^{*}$ & 0.108 & $0.144^{*}$ & 0.035 \\
\hline Stdev wage & -0.002 & $-0.781^{*}$ & -0.423 & -0.181 \\
\hline \multicolumn{5}{|l|}{ Distant History 1988-1996 } \\
\hline Number of unemployment spells & -0.011 & $0.467^{*}$ & -0.093 & $0.293^{*}$ \\
\hline Percentage unemployed & $-1.271^{*}$ & $-1.473^{*}$ & 0.010 & $-1.077^{*}$ \\
\hline Number of employment spells & $0.310^{*}$ & -0.192 & -0.168 & -0.244 \\
\hline Percentage employed & -0.010 & $-0.408^{*}$ & 0.099 & $-0.487^{*}$ \\
\hline Mean wage & -0.051 & $-0.265^{*}$ & -0.067 & 0.017 \\
\hline Stdev wage & $-0.320^{*}$ & 0.261 & 0.217 & 0.027 \\
\hline
\end{tabular}

NOTE: multivariate mixed proportional hazard model for unemployment duration and time until program entry; heterogeneous programs effects by program type, correlated unobserved heterogeneity in hazard rates, program effects are measured at program entry and constant for the remaining unemployment spell.

* denotes significance at $5 \%$ level.

Full estimation results given in table 7 . 
Table 5: Heterogeneous program effects by individual characteristics

\begin{tabular}{lccc}
\hline & Training & Job search & Other programs \\
& & & \\
Constant & -0.178 & 0.509 & -0.70 \\
& $(0.056)$ & $(0.043)$ & $(0.038)$ \\
Female & 0.344 & 0.138 & 0.314 \\
& $(0.095)$ & $(0.077)$ & $(0.067)$ \\
Austrian & 0.182 & 0.231 & 0.242 \\
& $(0.201)$ & $(0.127)$ & $(0.113)$ \\
Compulsory School & 0.235 & 0.130 & 0.190 \\
& $(0.105)$ & $(0.079)$ & $(0.071)$ \\
LR test $\chi^{2}(9)$ & & & \\
number of observations & 13283 & & \\
log Likelihood & -6015 & & \\
\hline
\end{tabular}

NOTE: multivariate mixed proportional hazard model for unemployment duration and time until program entry; heterogeneous programs effects by program type and selected individual characteristics; unobserved heterogeneity in hazard rates, program effects are measured at program entry and constant for the remaining unemployment spell; standard errors in parentheses.

Table 6: Time dependent program effects

\begin{tabular}{lccc}
\hline & Training & Job search & Other programs \\
& & & \\
0-30 days & -0.921 & 0.219 & -0.566 \\
& $(0.163)$ & $(0.085)$ & $(0.093)$ \\
31-60 days & -0.368 & 0.452 & -0.164 \\
& $(0.127)$ & $(0.091)$ & $(0.083)$ \\
more than 60 days & 0.294 & 0.443 & 0.307 \\
& $(0.055)$ & $(0.053)$ & $(0.042)$ \\
LR test $\chi^{2}(6)$ & 178 & & \\
number of observations & 13283 & & \\
log Likelihood & -5942 & & \\
\hline
\end{tabular}

NOTE: multivariate mixed proportional hazard model for unemployment duration and time until program entry; heterogeneous programs effects by program type; unobserved heterogeneity in hazard rates, program effects are measured at program entry and allowed to vary over the remaining unemployment spell; standard errors in parentheses. 


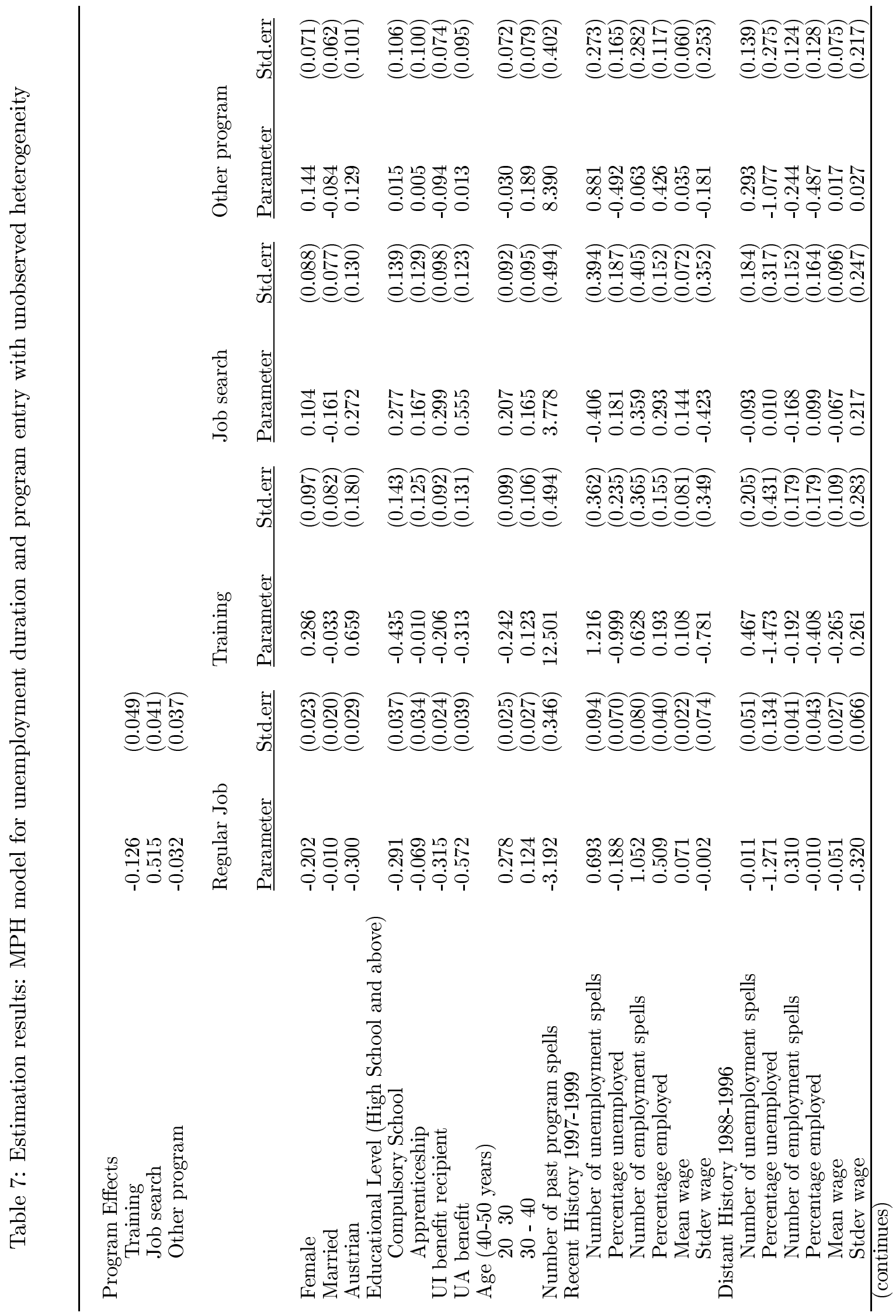




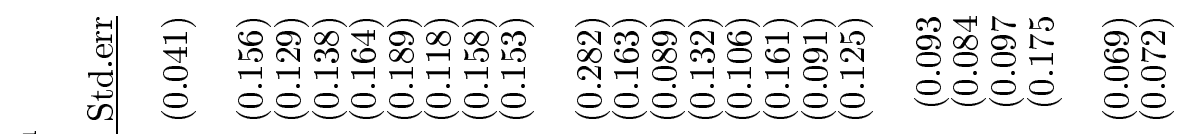

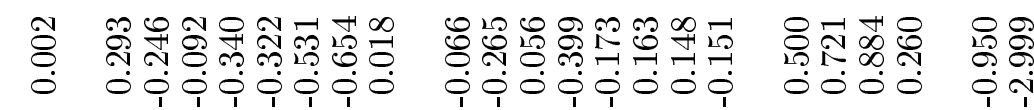

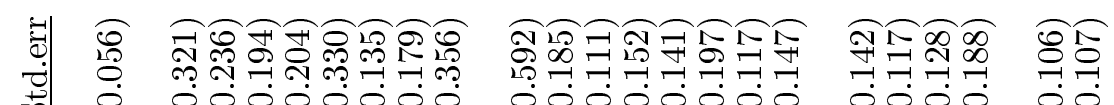

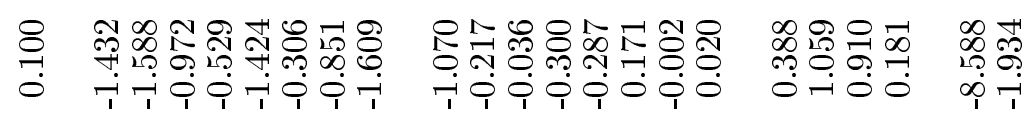

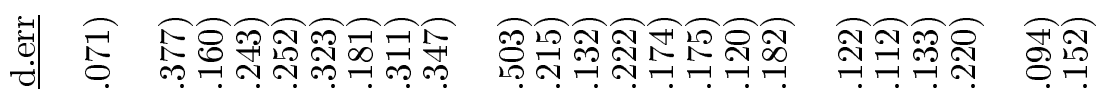
苟

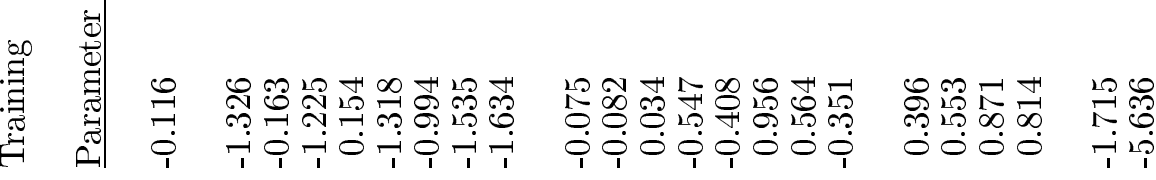

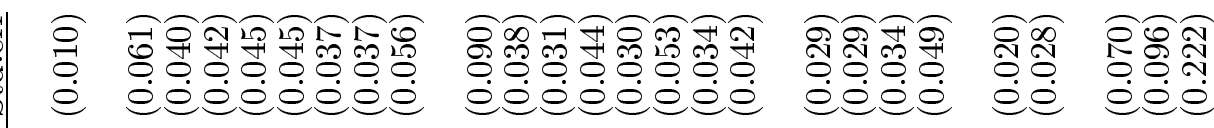

菊司

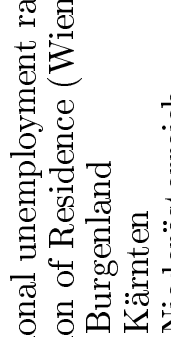

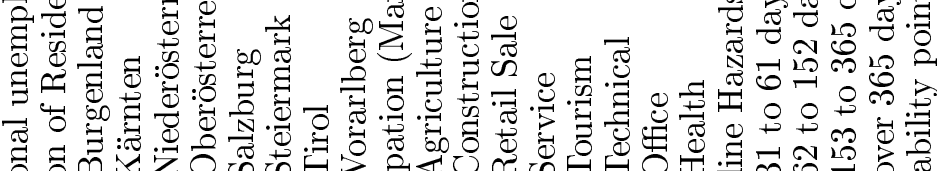

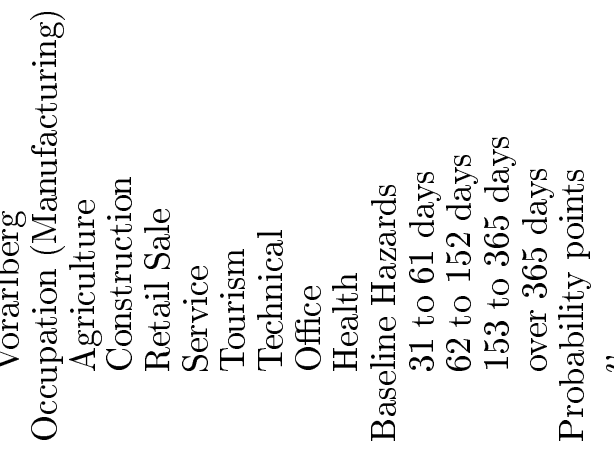

की

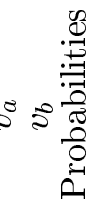


Figure 1: Empirical hazard rates: unemployment duration

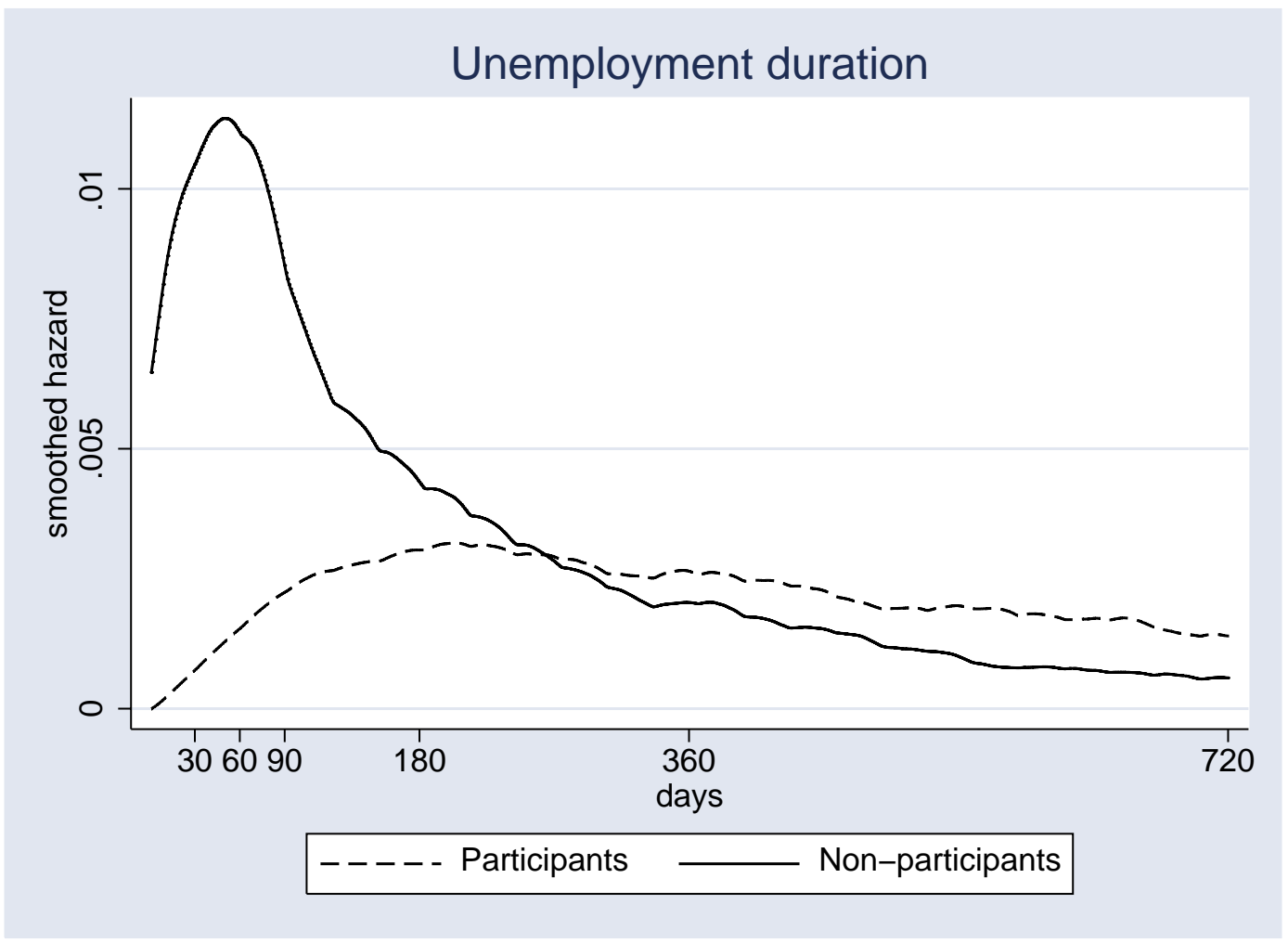


Figure 2: Empirical hazard rate: duration until entry into program

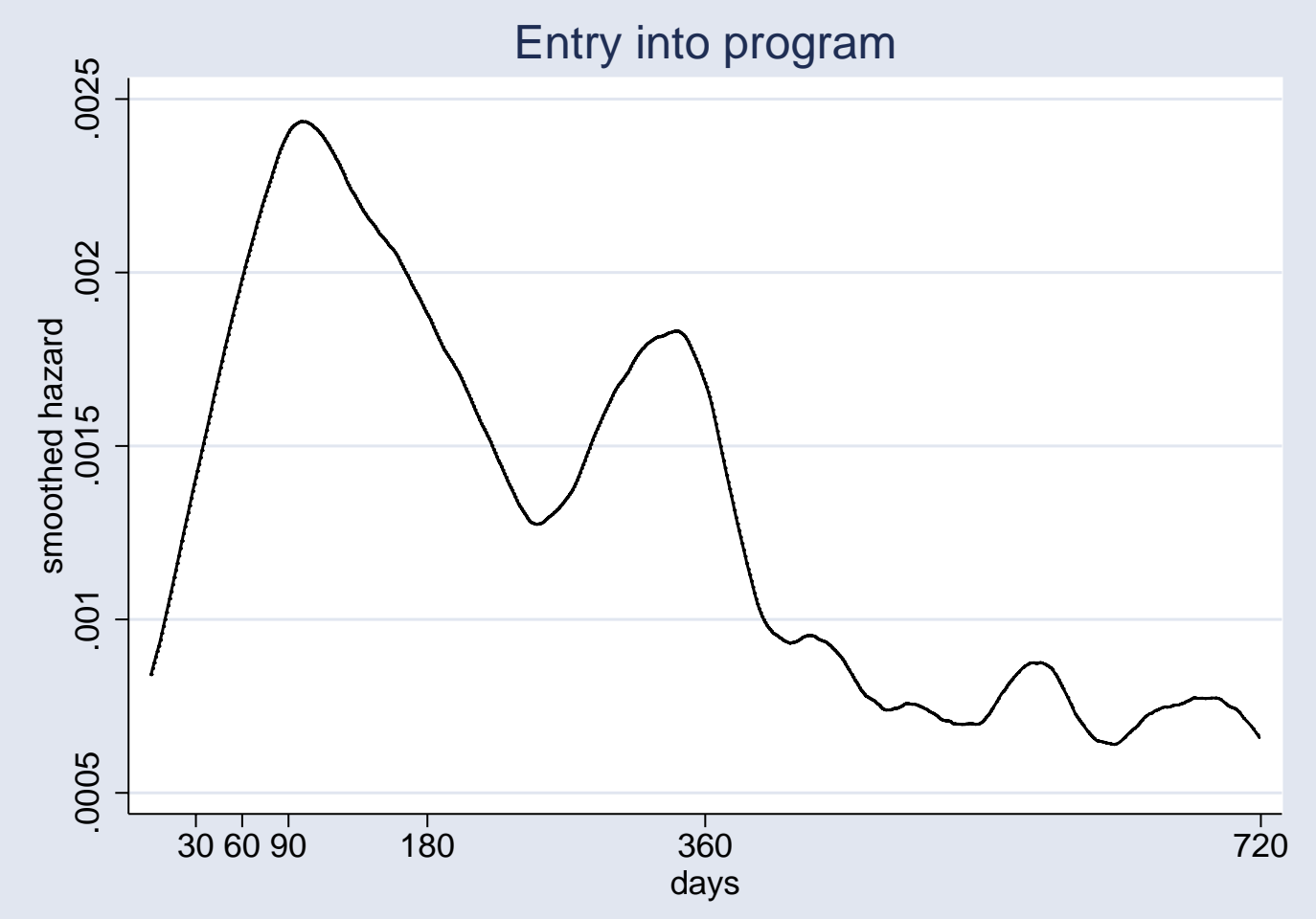

